\title{
COMO EN LAS CAVERNAS. PRIMITIVISMO Y PROGRESO EN LOS CUENTOS DE ÉPOCAS PASADAS DE EMILIA PARDO BAZÁN*
}

\author{
COMO EN LAS CAVERNAS. \\ PRIMITIVISM AND PROGRESS \\ IN EMILIA PARDO BAZÁN'S TALES OF PAST AGES
}

\author{
Gloria MorA**
}

Universidad Autónoma de Madrid

\begin{abstract}
RESUMEN. Entre 1880 y 1921, Emilia Pardo Bazán (1851-1921) publicó más de medio millar de cuentos y narraciones cortas en periódicos y revistas ilustradas de gran difusión en España e Hispanoamérica como El Imparcial, La Esfera, La Ilustración Artística, La España Moderna, La Ilustración Española y Americana, Blanco y Negro, etc. Algunos de estos cuentos se basaban en personajes y episodios de la Antigüedad, demostrando ser buena conocedora de las fuentes grecolatinas y bíblicas, pero me centraré en dos "cuentos prehistóricos» escritos en 1907 y 1912 (con antecedentes en algunos artículos en la prensa de los años 90), que tienen un doble interés: por un lado, presentar los avances y novedades de la investigación en la nueva y polémica ciencia de la Prehistoria, al tiempo que la autora aprovecha la confrontación barbarie-civilización de los estudios sobre la evolución humana para denunciar los problemas de la mujer en la sociedad contemporánea.
\end{abstract}

PALABRAS CLAVE: Emilia Pardo Bazán, Cuentos prehistóricos, Arte rupestre, Feminismo, Marqués de Cerralbo.

ABSTRACT. Between 1880 and 1921 Emilia Pardo Bazán (1851-1921) published more than half a thousand tales and short stories in newspapers and illustrated magazines of great diffusion in Spain and Latin America such a El Imparcial, La Esfera, La Ilustración Artística, La España Moderna, La Ilustración Española y Americana, Blanco y Negro, etc. Some of these tales were based on characters and episodes of Antiquity proving a good knowledge of ancient sources. In this paper I will focus on two "prehistoric» tales written in 1907 and 1912 (with background in some previous articles in the press) which have a double interest: on the one hand the author presents the advances and novelties of research in the new and controversial science of Prehistory, while she takes advantage of the confrontation barbarism-civilization raised in the studies on human evolution to denounce the problems of women in contemporary society.

KEYWORDS: Emilia Pardo Bazán, Prehistoric Tales, Paleolithic Art, Feminism, Marqués de Cerralbo.

* Este texto se enmarca en el Proyecto HAR2016-76940-P y es un extracto de una versión más amplia sobre Emilia Pardo Bazán y la Antigüedad que se publicará en T. Tortosa (ed.), La novela arqueológica o la ensoñación de la realidad (siglos XIX-XX). De relatos, sortilegios y mujeres, vol. II, Madrid, Polifemo, en preparación.

\footnotetext{
** Correspondencia a / Correspondence to: Gloria Mora. Universidad Autónoma de Madrid, Dpto. de Historia Antigua, Historia Medieval y Paleografía y Diplomática, Facultad de Filosofía y Letras, Campus de Cantoblanco (28049 Madrid) - gloria.mora@uam.es - https://orcid.org/0000-0003-0693-3365.

Cómo citar / How to cite: Mora, G. (2019), "Como en las cavernas. Primitivismo y progreso en los cuentos de épocas pasadas de Emilia Pardo Bazán», Veleia, 36, 57-71. (https://doi.org/10.1387/veleia.20830).
}

Recibido: 8 mayo 2019; aceptado: 4 junio 2019.

ISSN 0213-2095 - elSSN 2444-3565 / (C) 2019 UPV/EHU 
Emilia Pardo Bazán (1851-1921), condesa de Pardo Bazán (título de origen pontificio heredado de su padre), escritora seguramente poco leída hoy por el público en general, es, sin embargo, una de las pocas intelectuales españolas reivindicadas en los últimos años en los estudios sobre feminismo, tema sobre el que ya hay una ingente bibliografía a la que se anticipó Felipe Alaiz con la semblanza publicada en 1936 en La Revista Blanca (n. 369, 14 de febrero) como parte de la serie «Tipos españoles» (Trinidad 2009), continuada con la biografía de Carmen Bravo-Villasante (1962) y numerosos trabajos posteriores. Narradora y poeta, periodista, ensayista, crítica literaria y conferenciante, Pardo Bazán se distinguió por su defensa de los derechos de la mujer y de su independencia intelectual y económica, tanto a través de sus escritos (novelas, cuentos, ensayos) como en numerosísimos artículos periodísticos aparecidos en las principales publicaciones españolas y extranjeras entre 1876 y mayo de 1921, fecha de su muerte (Cook 1976; Paredes Núñez 1992; Pardo Bazán 2019).

Pionera y polémica en muchos campos, especialmente como introductora de la corriente naturalista en la novela española, también cabe atribuir a Pardo Bazán cierta dedicación por primera vez al género de la llamada "paleoficción", muy bien representado en la literatura inglesa y sobre todo francesa de finales del siglo xIx y primeras décadas del xx, y que ella conoció directamente gracias a sus viajes, sus lecturas y sus relaciones personales con algunos de los protagonistas de la nueva ciencia de la Prehistoria (Fernández Martínez 1991, Vázquez de Parga 1993, Guillaumie 2006 y 2013, Ruddick 2009, Martín Rodríguez 2015). Es precisamente este interés por la Prehistoria, plasmado en algunos cuentos, una novela breve y en artículos periodísticos, una de las facetas menos conocidas de Pardo Bazán: no se menciona en la última y monumental biografía de Isabel Burdiel (2019), aunque sí se le ha dedicado un interesante artículo reciente (Martín Rodríguez 2015). El objetivo de este texto no es hacer un estudio de carácter literario sobre dos relatos "prehistóricos» de Emilia Pardo Bazán ni tampoco un análisis historiográfico sobre la Prehistoria en su época, sino, más modestamente, presentar unas noticias sobre la relación de la escritora con las investigaciones coetáneas y con algunos de sus principales protagonistas en España y en Francia, y especialmente mostrar cómo utilizó ese pasado remoto a modo de espejo de la situación de las mujeres en la sociedad contemporánea ${ }^{1}$.

No está de más, para empezar, mencionar brevemente algunos datos biográficos, pues, si bien son conocidos por los historiadores de la literatura, quizás no lo sean tanto para los arqueólogos, y servirán para contextualizar las obras a las que me referiré después. Las fuentes son, fundamentalmente, los estudios que introducen sus Obras Completas, la mencionada obra de Burdiel 2019 y los Apuntes autobiográficos de Pardo Bazán, originalmente publicados como prólogo a Los pazos de Ulloa en 1886 y en una versión definitiva por Freire López 2001.

Emilia Pardo Bazán nació en La Coruña (la Marineda de muchos de sus escritos) el 16 de septiembre de 1851, en el seno de una familia de la alta burguesía gallega. Su padre, el político liberal progresista (diputado en Cortes en 1869 y 1873) José Pardo Bazán y Mosquera, dio a su única hija todas las facilidades para una educación de calidad que por entonces (y hasta época muy reciente) estaba reservada a los varones. Así, desde los 8 años Emilia tuvo acceso a la notable biblioteca paterna; a los 9 empezó a escribir poesía, y a los 15 el Almanaque de La Soberanía Nacional le publicó el cuento "Un matrimonio del siglo XIX», el primero de los más de 600 que escribiría a lo largo de su vida. Estudió además dos años en un colegio francés laico de Madrid protegido por la

\footnotetext{
1 Agradezco a los evaluadores del artículo sus valiosas sugerencias y referencias bibliográficas para mejorar el texto.
} 
Casa Real. En 1868, con 16 años, se casó con un joven estudiante de Derecho perteneciente también a la clase alta de Galicia, José Quiroga y Pérez Deza, de ideología política muy distinta a la de la familia Pardo Bazán, pues era carlista. Tuvieron tres hijos (Jaime, Blanca y Carmen) antes de separarse discretamente en 1884; Quiroga murió en 1912. En 1870, movida por el desencanto por los conflictos políticos tras la Gloriosa, toda la familia (los padres, Emilia y su marido) se trasladó a vivir a París y viajó por Europa hasta 1873, lo que facilitó la educación cosmopolita de Emilia y el aprendizaje de otras lenguas (inglés, italiano, alemán) además del francés que ya dominaba, pues era su deseo leer a los grandes escritores y filósofos en su lengua original. Nunca perderá la costumbre y el gusto por los viajes, especialmente para visitar las Exposiciones Universales o para impartir conferencias. A partir de 1876 publica regularmente en la prensa las crónicas de estos viajes (algunas reunidas después en libros), artículos sobre las tendencias literarias, artísticas y culturales europeas, y novelas y cuentos en los que deja constancia de sus ideas.

Pardo Bazán fue amiga de políticos e intelectuales de ideologías tan dispares como Antonio Cánovas del Castillo y Emilio Castelar, el pretendiente Don Carlos de Borbón y su representante en España (entre 1890 y 1899) Enrique de Aguilera y Gamboa, XVII marqués de Cerralbo, Benito Pérez Galdós, Juan Valera, Leopoldo Alas «Clarín», Juan Pereda, Francisco Giner de los Ríos, Miguel de Unamuno, Vicente Blasco Ibáñez, Rafael Altamira, José Lázaro Galdiano. Entre los extranjeros cabe mencionar a Víctor Hugo, a quien conoció en París en 1880, los hermanos Goncourt, Émile Zola, Alphonse Daudet y Guy de Maupassant, que tanto influyeron en ella y propiciaron su polémica incursión en defensa del realismo y el naturalismo en literatura (La cuestión palpitante, 1882) y en la escritura de novelas de este estilo, que introdujo en España con Los pazos de Ulloa (1886) y La madre naturaleza (1887).

Fue también la primera mujer que figuró activamente en ámbitos hasta entonces reservados al hombre, como el periodismo profesional o el desempeño de cargos académicos. En 1880 fundó y dirigió la Revista de Galicia. En 1890 publicó una serie de artículos bajo el título «La mujer española» en La España Moderna, editorial y revista literaria fundada por su gran amigo el empresario y coleccionista José Lázaro Galdiano, apreciados por su «sinceridad, dureza y feminismo». Entre 1891 y 1893 dirigió la revista Nuevo Teatro Crítico, título que homenajeaba a su admirado P. Feijoo, pionero defensor de los derechos de la mujer. Precisamente a Feijoo había dedicado un Ensayo crítico que obtuvo un accésit en el certamen organizado en Orense en 1878 para conmemorar el bicentenario de su nacimiento, en competencia con Miguel Morayta y Concepción Arenal (Freire López 1996, Barreiro Fernández 2003, Caballé 2018, 276 ss.) ${ }^{2}$. En 1892 creó la Biblioteca de la Mujer, dedicada a la instrucción de las mujeres mediante la publicación de obras nacionales y sobre todo extranjeras, y que se anunciaba como fruto de «La importancia que desde mediados del siglo va adquiriendo el destino de la mujer, y la agitación en favor de su cultura que se advierte en los pueblos más civilizados». Ella misma tradujo The Subjection of Women de John Stuart Mill (1869), que publicó con el título La esclavitud femenina. Ese mismo año de 1892 formó parte del Comité del Congreso Pedagógico Hispano-Portugués-Americano, celebrado en Madrid, con un discurso sobre «La educación del hombre y la de la mujer: sus diferencias». En el curso 1896-1897 impartió la cátedra de Literatura contemporánea en la recién fundada Escuela de Estudios Superiores del Ateneo, con 825 alumnos matriculados en las 11 sesiones que se desarrollaron entre enero y abril de 1897 (Villacorta Baños 1979, 149, cuadro 1; Quesada Novás 2006, 47). Fue la primera mujer

2 Pardo Bazán admiraba a Arenal, aunque no compartía sus puntos de vista radicales sobre cuál debía ser el papel de la mujer en la sociedad (entrega absoluta a la beneficencia, moral sin tacha); al parecer la admiración no fue recíproca (Caballé 2018, 315, 340, 343). Véase Cabrera Bosch 2007. 
elegida socia de número del Ateneo de Madrid en 1905, con número de carnet 7.925 (la noticia de su admisión apareció en La Época, el 15 de febrero de 1905), y en 1906 fue nombrada Presidente de la Sección de Literatura del Ateneo. En 1910 fue designada miembro del Consejo de Instrucción Pública. En 1912, socia de número de la Sociedad Matritense de Amigos del País. En 1916, con 65 ańos, se le concedió, por primera vez a una mujer, la cátedra de Literatura contemporánea de las lenguas neo-latinas en el Doctorado de la Facultad de Filosofía y Letras de la Universidad Central, creada expresamente para ella por el ministro de Instrucción Pública Julio Burell pese a las protestas de una parte del claustro de profesores: doce catedráticos votaron en contra, dos se abstuvieron, y los ocho que votaron a su favor fueron Elías Tormo, decano de la Facultad, Eloy Bullón, Miguel Morayta, José Ramón Mélida (antiguo compañero en la Escuela de Estudios Superiores del Ateneo), Andrés Ovejero, Cayo Ortega, Juan Gualberto López-Valdemoro de Quesada, conde de las Navas, y Emeterio Mazorriaga (Quesada Novás 2006, 55 ss.; Burdiel 2019, 603 ss.) ${ }^{3}$. Sus lecciones fueron publicadas póstumamente, en 1923, por Luis Araujo Costa con el título El lirismo en la poesía francesa, siendo el volumen XLIII y último de la colección de sus Obras Completas editada por la propia Pardo Bazán a partir de 1890. Pronunció, además, conferencias en universidades y otros centros españoles y europeos, destacando su discurso en la Société de Conférences de París el 18 de abril de 1899, sobre "La España de ayer y la de hoy» (acerca del llamado "problema de España», es decir, la pérdida de las colonias y la crisis del 98). Pese a su fama, por tres veces se le denegó el ingreso en la Real Academia Española (en 1889, 1891 y 1912).

Sus biógrafos han destacado en Pardo Bazán su constante preocupación por los acontecimientos políticos y culturales de Espańa y de Europa y por el papel de la mujer en la sociedad, reflejados en sus múltiples artículos, ensayos y cuentos, así como su temprana vinculación — desde los primeros viajes a Europa en 1870 - a las nuevas corrientes de pensamiento impulsoras del progreso en España, representadas por el Ateneo y sobre todo por la Institución Libre de Enseñanza. En este sentido fue decisiva su amistad con Giner de los Ríos, a quien dedicó un sentido «Elogio» cuando murió (La Ilustración Artística, n. ${ }^{\circ}$ 1.731, 1 de marzo de 1915), y con otros miembros de la ILE. Como consecuencia de estas relaciones, Emilia Pardo Bazán participó, incluso económicamente, en algunas empresas promovidas por la ILE (Burdiel 2019, 137) y, más adelante, por las instituciones herederas del regeneracionismo: la Junta para Ampliación de Estudios e Investigaciones Científicas (JAE), fundada en 1907, y la Residencia de Estudiantes, en la que en diciembre de 1916 pronunció una conferencia sobre «El porvenir de la literatura después de la guerra», publicada en 1917.

Por lo que respecta a su formación intelectual, muy avanzada para la época, en sus Apuntes autobiográficos Pardo Bazán explica cuáles habían sido sus lecturas en la infancia y la adolescencia: las fuentes clásicas (Homero, Jenofonte, Tito Livio, Plutarco sobre todo), la Biblia, el famoso Anacarsis (Voyage du jeune Anacharsis en Grèce dans le milieu du IV siècle, París 1787) del Abbé JeanJacques Barthélemy ${ }^{4}$, y algunas obras históricas que le proporcionaron un amplio conocimiento de la Historia en general y de la Antigua en particular. Como veremos, también se interesó por la arqueología, estando al tanto de las novedades en descubrimientos y teorías. Precisamente algunos de sus relatos (la mayoría recopilados en varias colecciones: Cuentos de épocas pasadas, Cuentos antiguos, Cuentos trágicos) están situados en un pasado más o menos remoto que sirve como punto de

3 En este curso de Doctorado solo hubo un alumno matriculado oficialmente, Pedro Sainz Rodríguez (Burdiel 2019, 608), pero hay que recordar que, en esas primeras décadas del siglo, como reflejan las actas de exá- menes, la mayoría de los alumnos se matriculaban por libre.

4 Pudo leerlo en la traducción al castellano publicada en París en 1845. 
comparación con el presente (que no suele salir bien parado), así como de marco para explicar situaciones actuales y reclamar, con la legitimidad de los modelos antiguos, incluso bíblicos, la independencia de la mujer.

Justamente la época de máximo sometimiento de la mujer, y al mismo tiempo del comienzo de su lucha por la libertad, la sitúa Pardo Bazán en la época más antigua de la humanidad, la Prehistoria, que entonces era objeto de una nueva disciplina académica en pleno desarrollo durante la segunda mitad del siglo xix, y tema de las tertulias intelectuales de moda sobre todo en Francia, de novelas, libros de divulgación y obras artísticas que, como veremos, ella demuestra conocer muy bien gracias a sus viajes y a su amistad con el selecto círculo intelectual francés y, desde luego, a su insaciable curiosidad. También en España, como ha demostrado recientemente José María Lanzarote Guiral (2017), desde 1880 abundaban en la prensa y semanarios ilustrados (La Ilustración Española y Americana, Alrededor del mundo) las noticias e imágenes sobre descubrimientos de arte prehistórico, con ilustraciones generalmente tomadas de publicaciones francesas o inglesas como The Illustrated London News (Lanzarote Guiral 2017, 804). En cambio, la prensa española silencia las pinturas de Altamira descubiertas en 1879 por Marcelino Sanz de Sautuola, lo que podría explicarse por el descrédito derivado de las acusaciones de falsificación lanzadas por los prehistoriadores franceses, descrédito que se prolongó hasta que Émile Cartailhac reconoció públicamente la autenticidad de las pinturas con el célebre «Mea culpa d'un scéptique» pronunciado durante el Congrès de l'Association Française pour l'Avancement des Sciences celebrado en Montauban en agosto de 1902 (Cartailhac 1902, Moro Abadía \& González Morales 2004, 119; Ayarzagüena Sanz 2006).

Emilia Pardo Bazán conocía bien la literatura especializada. En 1877 había publicado en $\mathrm{La}$ Ciencia Cristiana (vol. IV-V), seria revista científica de los jesuitas, un largo artículo, asombrosamente documentado, titulado: «Reflexiones científicas contra el darwinismo» (Pardo Bazán 1973), en el que confrontaba ciencia y fe pero desde su propio punto de vista como creyente, para demostrar que no constituía un peligro para el catolicismo (Paredes Núñez 1979, 84), integrándose así en el candente debate coetáneo sobre la conciliación ciencia-religión a propósito del darwinismo (Glick 1982, Pelayo 2015). Años después, el 7 de agosto de 1893, publicó «Cuento primitivo» en Los lunes de El Imparcial (dirigido por José Ortega Munilla), un relato no evolucionista sobre la creación de Adán y Eva y, sobre todo, en defensa de la inocencia e independencia de Eva, personificación de la mujer, respecto del hombre. En la Escuela de Estudios Superiores del Ateneo tuvo ocasión de familiarizarse aún más con las teorías evolucionistas, sobre todo con las lecciones de Manuel Antón y Ferrándiz, catedrático de Antropología de la Universidad de Madrid (Villacorta Baños 1979, 140-144).

Un primer acercamiento periodístico a la comparación entre la sociedad prehistórica, equivalente a la barbarie, y la sociedad contemporánea, supuestamente civilizada, lo encontramos en el artículo publicado el 16 de septiembre de 1901 en la revista de Barcelona La Ilustración Artística n. 1029 (p. 602), titulado "Como en las cavernas», perteneciente a su serie de crónicas La vida contemporánea. Denuncia la violación e intento de asesinato de una joven trabajadora en Madrid, "en medio de una sociedad que se dice civilizada», calificando la actitud de los atacantes como propia de la época prehistórica, y también la de los policías y jueces que no protegían a las mujeres, presa fácil para los hombres. Pero si el artículo en una revista de gran difusión tuvo un impacto grande - también por la crudeza del tema-, la misma idea expresada años después en forma de cuento será quizá más efectiva. Me centraré, pues, en dos relatos que se complementan, pues el primero, muy breve, parece un esbozo del segundo.

"Progreso" es un cuento publicado en Los Lunes de El Imparcial el 12 de agosto de 1907, y se incluyó en la serie recopilada por H. L. Kirby en el t. III de las Obras Completas de Pardo Bazán 
bajo el título Cuentos de épocas pasadas (Pardo Bazán 1907, 196-198). Son relatos ambientados en distintos momentos, desde los tiempos prehistóricos y la Grecia y Roma clásicas hasta la época moderna. En "Progreso», Pardo Bazán presenta una imagen de la humanidad prehistórica acorde con las ideas tradicionales sobre la evolución social y cultural del hombre representada por ciertos avances significativos: el paso de la promiscuidad a la monogamia, la búsqueda de un asentamiento estable, el descubrimiento del fuego. Los protagonistas, Indán la del pelo de oro y Bero el cazador, jóvenes miembros de una tribu nómada, descubren el modo de conservar el fuego causado por un rayo y huyen «llevándose, fruto de su unión monogámica, el hogar recién nacido».

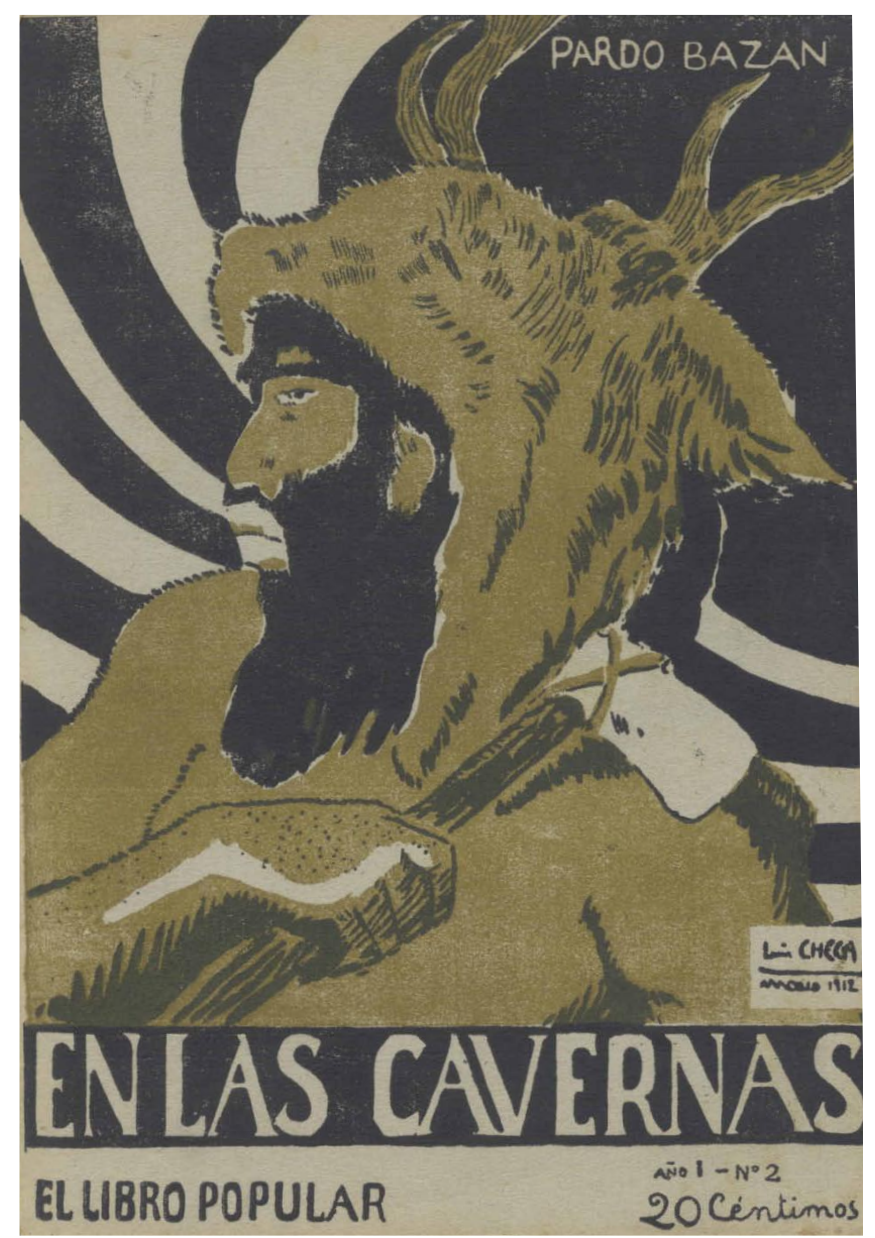

Figura 1. Portada de En las cavernas de Emilia Pardo Bazán, con ilustración de Luis Checa (Madrid, El Libro Popular, 1912)

Este mismo esquema se repite en la novela corta En las cavernas, obra de encargo publicada en 1912 como n.o 2 de la colección El Libro Popular, con siete ilustraciones, más la de portada, de Luis Checa (Correa Román 2001) (fig. 1). Cabe recordar que Pardo Bazán ya había utilizado en 
1901 un título muy parecido, «Como en las cavernas», en el artículo citado de La Ilustración Artística, para denunciar la desigualdad social y jurídica de la mujer. Al igual que en «Progreso», la narración se sitúa entre dos momentos clave de la evolución del hombre, representados por los ancianos que comen carne cruda y aman el nomadismo, y los jóvenes que ya conocen y aprecian el fuego y sueñan con asentarse. En ambos relatos, pero de forma más desarrollada en el último, Pardo Bazán plasma las ideas que aparecían en las publicaciones científicas y de divulgación, en la literatura y en las reconstrucciones artísticas de la vida en la Prehistoria, ideas centradas en la evolución social, tecnológica y cultural del hombre, del Paleolítico al Neolítico, sin nombrar estos períodos. Así, el protagonista de En las cavernas, el soñador e inteligente Napal, planea la fundación de una nueva sociedad que se beneficiaría de sus «inventos»: la agricultura, el pastoreo, la domesticación de lobos-perros y cabras, el paso de la cueva a los sofisticados palafitos en cuya existencia se creía entonces, la monogamia y la familia, la práctica de ceremonias funerarias, el arte. Napal y su amada Damara representan la transición de las tribus cazadoras, nómadas y promiscuas a las sociedades sedentarias dedicadas a la agricultura y la ganadería: un paso hacia la civilización (Guillaumie 2013). De nuevo aparece el fuego como elemento definitorio de evolución; el sentimiento espiritual o religioso vinculado a un «fetiche protector» o amuleto al que adora la horda; el nacimiento del arte vinculado a la magia, que consistía en la representación pictórica de animales y en la práctica de danzas propiciatorias de la caza, y por supuesto la rebelión de la mujer contra su destino de esclava de la tribu y en defensa de la monogamia (la institución del matrimonio) como única forma de libertad.

Estos dos relatos reúnen los tópicos coetáneos sobre la vida en la Prehistoria representados en la literatura y el arte: la vida errante o en cuevas, la lucha del hombre contra las fieras, la fabricación de útiles y armas, la práctica de la pintura con sentido mágico, la caza del mamut, etc. (Moser \& Gamble 1997, 190). Son imágenes que sirven para marcar la diferencia con la civilización: la vivienda estable, los vestidos de pieles y los adornos de las mujeres, la monogamia y la familia, los alimentos cocinados... (Stoczkowski 1997, 260). Se trata de una Prehistoria imaginada de larga tradición que suple la falta de datos científicos en la época, y que resulta tan verosímil que aún permanece en producciones literarias y artísticas actuales (Stoczkowski 1997, 253 ss.).

Por otro lado, en los relatos de Pardo Bazán se pueden reconocer las teorías más aceptadas entonces, derivadas de los estudios de antropólogos y etnólogos sobre los aborígenes de Australia o los bosquimanos de África, utilizados como referentes para la comprensión de las sociedades prehistóricas. Se recoge, por ejemplo, la tesis formulada por Salomon Reinach en su artículo «L'Art et la magie» (Reinach 1903) y en un libro posterior, Répertoire de l'art quaternaire (Reinach 1913, 135), recogida por Louis Capitan, el abate Breuil y otros prehistoriadores de comienzos de siglo y aplicada también al arte rupestre cantábrico y levantino (Cabré Aguiló 1915, Richard 1993, Moro Abadía \& González Morales 2004, 134-135). Reinach había elaborado esta teoría a raíz del descubrimiento de las pinturas rupestres de la cueva de Font-de-Gaume por Denis Peyrony en 1901, estudiadas y publicadas poco después por Capitan. En la presentación de Font-de-Gaume que Capitan y Breuil hicieron durante una sesión de la Académie des Inscriptions et Belles-Lettres en 1903, mencionaron la tesis de Salomon Reinach que explicaba la representación de animales como una práctica religiosa o fetichista cuya finalidad era ayudar mágicamente a la multiplicación de los animales representados, necesarios para la subsistencia, comparable a los tótems de los pueblos «salvajes» contemporáneos y a las danzas de los aborígenes australianos destinadas a favorecer la multiplicación de los canguros (Capitan \& Breuil 1903, 128-129). Por el contrario, Émile Cartailhac y la comunidad científica en general defendían «el arte por el arte», por puro sentido estético (Moro Abadía \& González Morales 2004, 131-133). Pardo Bazán, por su parte, cree en el sentido espi- 
ritual del arte rupestre: «La humanidad, en ocasiones, da muestras de espiritualismo, de aquel instinto estético que ya reveló en las cavernas o paraderos de las edades primitivas, al esculpir y pintar figuras llenas de espontaneidad, que delatan profunda observación de la naturaleza», decía en un artículo en el que denunciaba y lamentaba la destrucción de la catedral de Reims en los inicios de la Gran Guerra (Pardo Bazán 1914).

Podemos intuir las fuentes literarias y artísticas que Pardo Bazán utilizó en estos relatos, aunque no las cite. Es lógico pensar que sus referentes sean fundamentalmente franceses. En primer lugar, la muy exitosa obra divulgativa de Louis Figuier, L'homme primitif (1870), que tuvo varias ediciones muy bien ilustradas por Émile Bayard y Ernest-Jean Delahaye (Blanckaert 1993); de hecho, Pardo Bazán describe útiles y objetos de adorno hallados en excavaciones tal como aparecen representados en Figuier, como el «blanco peine, hecho del espinazo de un pez» con el que la doncella Indán "recogía su pelo de luz» (Pardo Bazán 1907 / 1973, 197; Figuier 1870, 178 fig. 103). También el ensayo Les Origines (1895) y la serie de relatos «prehistóricos» de J. H. Rosny Les Âges Farouches (desde 1892) mera novela de tema prehistórico (Dagen 1994, 69). Probablemente los protagonistas masculinos de los dos relatos de Pardo Bazán, especialmente Napal, estén basados en el personaje de Vamireh, el joven que asombraba a la horda por su habilidad y fuerza en la caza y su talento para tallar el hueso, la madera y el marfil. Otra fuente de inspiración debió ser la pintura de la «moda prehistórica»: obras de Léon-Maxime Faivre, Fernand Cormon, Emmanuel Benner y especialmente las muy documentadas «restituciones» realizadas por Paul Jamin (Lagardère 1990, Dagen 1994, Stoczkowski 1997, Moser \& Gamble 1997, Moser 1998, Ducros eds. 2000, Lafont-Couturier et al. 2003). El prehistoriador Louis Capitan elogió a Jamin como «le peintre préhistorien» porque coleccionaba, estudiaba y reproducía con exactitud los útiles prehistóricos, pero también como «un anthropologiste érudit» por sus reconstrucciones de la vida en la Prehistoria; para pintar su último cuadro, Le peintre décorateur (fig. 2) se había inspirado directamente en las notas, dibujos, calcos y acuarelas de las pinturas de Font-de-Gaume proporcionados por Capitan (1903, 488489). Quizá Pardo Bazán conoció también las sugerentes ilustraciones de la obra Nebula to Man de Henry R. Knipe, publicada en 1905 (Moser \& Gamble 1997, 203-204). Los dibujos de Luis Checa - de quien no he encontrado datos- para En las cavernas recogen en parte este rico conjunto de modelos iconográficos: la portada reproduce el tópico del hombre primitivo cubierto por pieles de animales y armado con un hacha de piedra, y en las figuras que acompañan el texto aparece la caza del elefante, la bella Damara con su collar de conchas o la lucha de los dos rivales por la posesión de la mujer.

Hay que añadir a este repertorio los panoramas, dioramas y reconstrucciones de la vida en la Prehistoria que Pardo Bazán había tenido la oportunidad de ver en las Exposiciones Universales de París de 1889 y 1900, y que había descrito como periodista para la prensa española. Así, en $A l$ pie de la Torre Eiffel comenta su visita a la Exposición de 1889, que conmemoraba el centenario de la Revolución Francesa. Destacan sus comentarios acerca de la sección «Historia de la habitación humana" (Histoire de l'habitation) creada por el arquitecto Charles Garnier (autor de la Ópera de París), que comprendía desde las cuevas "troglodíticas» y las viviendas lacustres hasta los palacios del Renacimiento italiano: era un "ensayo de exposición retrospectiva de la vivienda humana», buena lección de Historia «vista» y, por tanto, superior desde el punto de vista pedagógico a la Historia

5 Nom de plume de los hermanos Joseph-Henri y Séraphin-Justin Böex hasta 1908. De J. H. Rosny Aîné es La guerre du feu. Roman des âges farouches (1909), novela en la que se basa la película de Jean-Jacques Annaud $L a$ guerre du feu, de 1981. 
«verbal o leída», aunque no del todo logrado (Pardo Bazán 1889, 235-238). En palabras de Nils Müller-Schlessel, la Exposición Universal de 1889 constituyó la presentación internacional de la arqueología prehistórica (Müller-Schlessel 2001, 396). No solo por la serie de 44 estructuras dispuestas a lo largo del Quai d'Orsay, frente a la Torre Eiffel (gran símbolo del progreso tecnológico), a través de las cuales Garnier pretendía mostrar el progreso espiritual, material e intelectual de la humanidad, sino además por la exposición dedicada a la historia del trabajo (Histoire du travail) en el pabellón de las Artes Liberales en el Campo de Marte, que mostraba siete escenas con personajes de tamaño natural recreando los principales períodos prehistóricos a partir de elementos de la cultura material y de hallazgos óseos conservados en los museos (Müller-Schlessel 2001, 395399) (fig. 3). En Cuarenta días en la Exposición recoge sus impresiones de la Exposición Universal de París de 1900, escritas por encargo de José Ortega Munilla y publicadas en El Imparcial (Jiménez Morales 2017). El capítulo XXVII, titulado "Arte antiguo», está dedicado a la exposición en el Petit Palais de muestras del arte francés desde época prehistórica hasta 1900 (Pardo Bazán 1900, 187 ss.), y en el capítulo XXVI, "Atracciones», describe los "panoramas» y dioramas realizados con fines educativos; al menos tres de ellos estaban dedicados a la historia del mundo antes de la aparición del hombre (Pardo Bazán 1900, 179-183). Ambas exposiciones tuvieron mucho éxito tanto en el número de visitantes como en las crónicas de prensa (pese a las críticas de Pardo Bazán, quien por falta de interés no llegó a visitar el Pabellón de las Artes Liberales con su sección antropológica y la muestra sobre la historia del trabajo, que se limita a mencionar: 1889, 194).

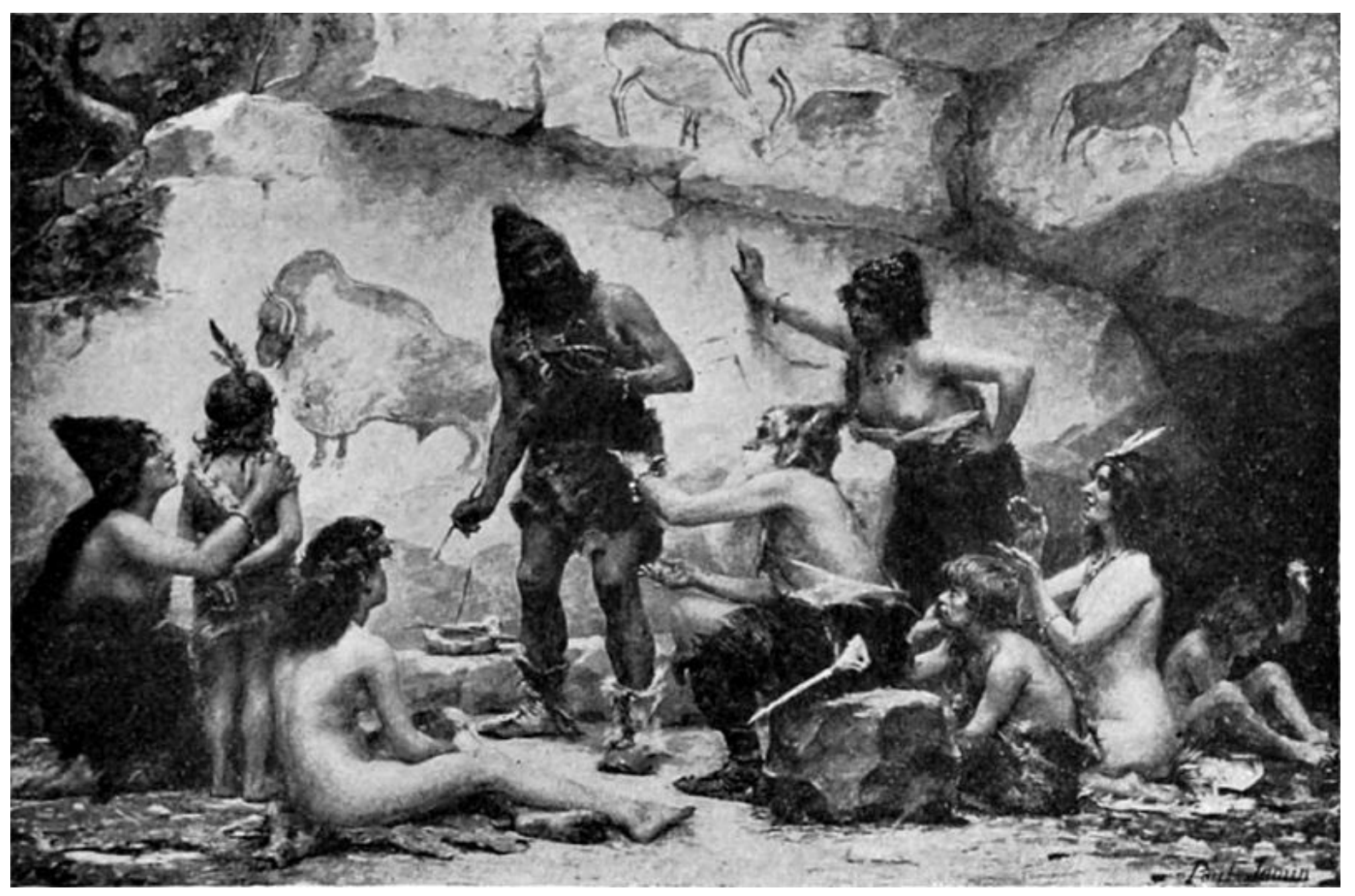

Figura 2. Paul Jamin, Un peintre décorateur à l'âge de la pierre. Le portrait de l'aurochs (1903). De Capitan 1903, 489, fig. 2 


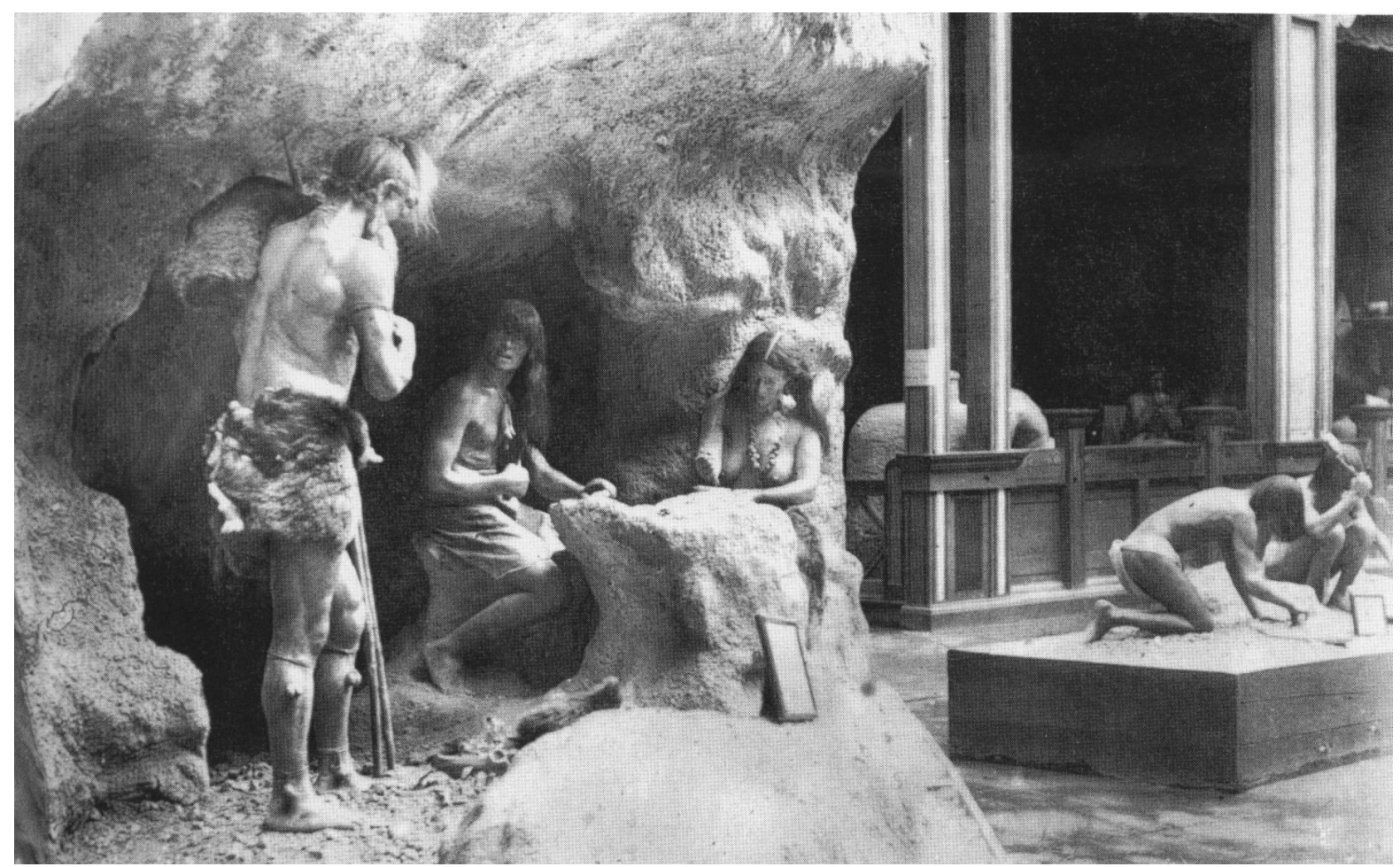

Figura 3. Recreación del Hombre de Cro-Magnon, Exposición Universal de París, 1889. Fotografía anónima, Bibliothèque du Musée de l'Homme, París. De Lafont-Couturier et al. 2003, 57, 40.

Es interesante señalar, como prueba de las relaciones de Pardo Bazán con prehistoriadores, sus notas retrospectivas sobre la conversación que durante una cena organizada por una sociedad científica en 1887 había mantenido con "un sabio de tomo y lomo», el ilustre Gabriel de Mortillet, uno de los grandes pioneros de la Prehistoria francesa, acerca de los cráneos conservados en los museos de Antropología españoles y especialmente sobre la sorprendente ausencia de cráneos "gallegos» (Pardo Bazán 1889, 201-202; Richard 2012). Precisamente Mortillet intervino activamente en el X Congrès International d'Anthropologie et d'Archéologie Préhistoriques celebrado en París en agosto de 1889, coincidiendo con la Exposición, como refleja la crónica redactada por otro ilustre participante, Juan Vilanova y Piera, también pionero de la Prehistoria, delegado de España en este Congreso y a quien con seguridad conocía Pardo Bazán; intervino con una síntesis sobre la prehistoria española en la que no mencionó las pinturas de Altamira (Vilanova y Piera 1890; Congrès 1891, XXII, 250-251).

En cuanto a influencias más directas, podemos señalar la del marqués de Cerralbo, gran promotor de las investigaciones arqueológicas en Espańa a comienzos del siglo xx. El inicio de En las cavernas recuerda poderosamente las primeras páginas de un escrito de Cerralbo sobre la caza del elefante en las llanuras pantanosas de Iberia. Dice Pardo Bazán: «La estepa que después se llamó Iberia prolongábase, al parecer, sin fin, pantanosa todavía, con densa vegetación de cañas y juncos, y arbolados a trechos; [...]. Y la esperanza de la mísera ralea era que, a deshora, asomase por las ciénagas la manada de elefantes» (Pardo Bazán 1912, 1). Y Cerralbo 1909, 12-15: «Por los inconmen- 
surables pantanos bullen y desraízan bambúes, los mastodontes, los elefantes y los supra-colosos dinoterios [...] y la nómada tribu contempla desde la cima [...] las manadas de elefantes...».

Esta referencia indicaría el conocimiento por Pardo Bazán de los recientes descubrimientos que su «erudito y caballeroso amigo el marqués de Cerralbo» (Pardo Bazán 1903) estaba realizando en esos años, 1909-1911, en el yacimiento paleolítico soriano de Torralba del Moral; después, entre 1914 y 1916, excavaría también en la cercana estación de Ambrona con los mismos resultados. Los hallazgos consistían en los restos fósiles de grandes mamíferos — sobre todo las defensas - como elefantes y rinocerontes, acompańados de bifaces y otros útiles de piedra que se habrían utilizado para darles muerte tras empujarlos a un terreno entonces pantanoso donde quedaron atrapados. Esto demostraría, para Cerralbo, la coexistencia del hombre (Homo Heidelbergensis) y de animales del Pleistoceno y resolvería, por tanto, las discusiones anteriores sobre la antigüedad del hombre (Santonja et al. 2005; Barril Vicente 2016, 128) (fig. 4).

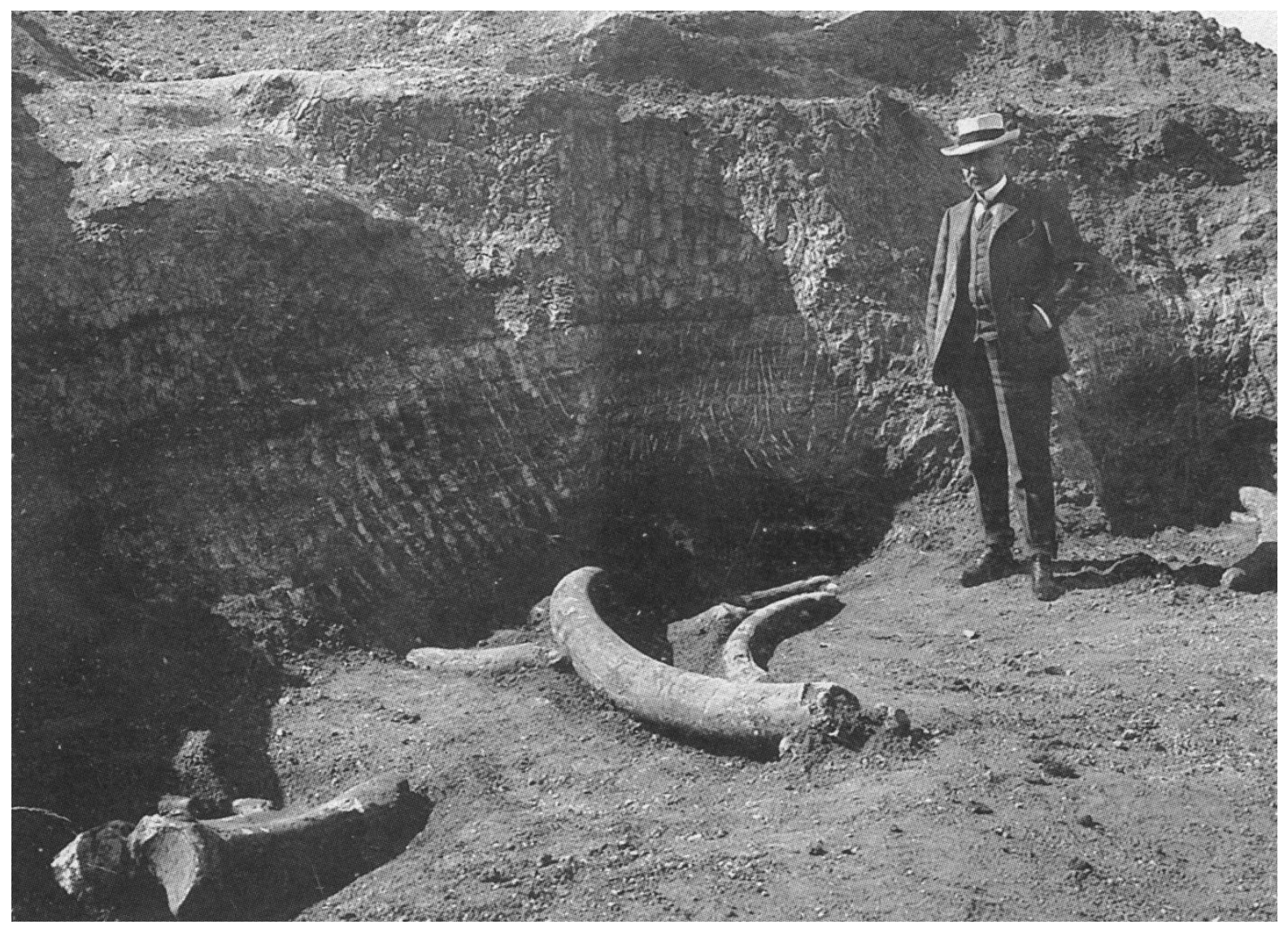

Figura 4. El marqués de Cerralbo en las excavaciones de Torralba (Soria), en Páginas de la Historia Patria por mis excavaciones arqueológicas, I, lám. VI, 2. De Navascués Benlloch et al. 2008, 27

Los hallazgos de Torralba habían sido presentados por Cerralbo ante la Real Academia de la Historia el 26 de diciembre de 1909, inmediatamente después de la primera campaña, indicando además con orgullo la visita del paleontólogo Édouard Harlé para «ver, estudiar y definir» el yaci- 
miento tras tener noticia de los descubrimientos (Aguilera y Gamboa 1909, 24-25). Tres años después lo hizo en un foro internacional, el XIV Congreso Internacional de Antropología y Arqueología Prehistóricas celebrado en el mes de septiembre de 1912 en Ginebra, al que acudió como representante de la Real Academia de la Historia y en el que coincidió con el abate Breuil y Hugo Obermaier, pioneros del estudio de las cuevas cantábricas y del arte rupestre en Espańa (Aguilera y Gamboa 1913). Como presidente de la Comisión de Investigaciones Paleontológicas y Prehistóricas fundada en 1912 por la JAE, Cerralbo mantenía ya excelentes relaciones profesionales y personales con los más prestigiosos prehistoriadores, paleontólogos y arqueólogos franceses, como Salomon Reinach, Émile Cartailhac y el mencionado Harlé. Sobre el mismo tema, los descubrimientos de Torralba, habló Cerralbo también en el IV Congreso de la Asociación Española para el Progreso de las Ciencias, celebrado en Madrid en junio de 1913 (Aguilera y Gamboa 1915) y al que es posible que asistiera Pardo Bazán. Pero también pudo conocer estas novedades en alguna de las tertulias y reuniones culturales organizadas por el marqués de Cerralbo en su palacio madrileńo de la calle de Ventura Rodríguez, a las que era asidua junto con otras personalidades de la alta sociedad, la política y la ciencia (el Duque de Alba, Eduardo Dato, Marcelino Menéndez Pelayo, Juan Catalina García López, José Ramón Mélida, Rodrigo Amador de los Ríos, José Lázaro Galdiano, etc.), pues el Marqués solía presentar sus trabajos históricos y arqueológicos en esas reuniones (Navascués Benlloch et al. 2008, 27) ${ }^{6}$. Sabemos también de la costumbre de intercambiarse obras; en el archivo del Museo Cerralbo se conservan una tarjeta y dos cartas incompletas y sin fecha de Pardo Bazán a Cerralbo que documentan su amistad y estima mutua ${ }^{7}$. El primer documento es un tarjetón de agradecimiento de Pardo Bazán, con fecha de 24 de junio de 1918, por el envío de la obra Las necrópolis ibéricas, que admira "como argumento histórico de primera fuerza y como testimonio de acendrado españolismo» ${ }^{8}$; también es interesante una carta incompleta (no se conserva la primera cuartilla con la fecha) en la que Pardo Bazán alude a alguna excursión arqueológica con Cerralbo: "[...] y así conocer, guiada por un cicerone tan docto en la materia, los restos de la España celtíbera, que ojalá vayan saliendo a la luz».

Emilia Pardo Bazán murió en Madrid el 12 de mayo de 1921, sin llegar a ver la Exposición de Arte Prehistórico Español que se inauguraría unos días después. En 1926 se erigió un monumento en su memoria, obra de Pedro Muguruza y Rafael Vela, ante el Palacio de Liria y frente a su casa en la calle de la Princesa, por suscripción de mujeres españolas y argentinas a iniciativa de la Duquesa de Alba. Dado su demostrado interés por la Prehistoria, época que le sirvió de referencia para denunciar en algunas obras literarias y en artículos la situación de desigualdad, marginación y violencia sufrida por las mujeres desde el principio de los tiempos y, en un marco más general, la barbarie versus la civilización, no deja de ser una oportuna casualidad que su cátedra de Literatura en la Universidad Central fuera destinada en 1922, con la denominación de «Historia Primitiva del Hombre», al prehistoriador alemán Hugo Obermaier, a quien debió de conocer, pues pertenecían al mismo círculo intelectual en torno a la JAE y la Residencia de Estudiantes formado por el duque

6 Por ejemplo, los estudios que reunió en su obra inédita Páginas de la Historia Patria por mis excavaciones arqueológicas (5 vols.), merecedora del Premio Martorell en 1911, que se conserva en el Archivo del Museo Cerralbo. El t. I está dedicado a Torralba.

7 El archivo del Museo Cerralbo (Madrid) se encuentra actualmente en pleno proceso de catalogación, por lo que es posible que en el futuro aparezcan más cartas de Emilia Pardo Bazán. Agradezco a Irene Galvañ Martínez, del Departamento de Investigación y Colecciones del Museo, su amabilidad al localizar esta documentación y permitirme su consulta.

8 Se trata de la publicación de la intervención de Cerralbo el 22 de octubre de 1915 en el V Congreso de la Asociación Española para el Progreso de las Ciencias celebrado en Valladolid, t. II, Madrid, s.a. [¿1916?]. 
de Alba, el marqués de Cerralbo, José Ortega Munilla y José Ortega y Gasset entre otras personalidades.

En conclusión, por su demostrado conocimiento de los descubrimientos y las teorías en el ámbito de la Prehistoria, de las obras de divulgación y de la literatura y el arte sobre este período, que sin duda inspiraron su propia obra, Emilia Pardo Bazán merece una investigación exhaustiva que revalorice sus aportaciones al género de la paleoficción española.

\section{BiBLIOGRAFÍA}

Aguilera y Gamboa, E., Marqués de Cerralbo, 1909, «El cuaternario elefantino yacimiento de Torralba», en: E. Aguilera y Gamboa, El Alto Jalón. Descubrimientos arqueológicos. Discurso por el Excmo. Sr. Don Enrique de Aguilera y Gamboa, Marqués de Cerralbo, individuo de número de la Real Academia de la Historia, leido en la Junta Pública del 26 de diciembre de 1909, Madrid: Imprenta de Fortanet, 11-25.

Aguilera y Gamboa, E., Marqués de Cerralbo, 1913, "Torralba, la plus ancienne station humaine de l'Europe?», en: Congrès international d'anthropologie et d'archéologique préhistoriques. Compte rendu de la XIVe sesión. Genève 1912. Publié par les soins de M. Waldemar Deonna, I, Genève: Imprimerie Albert Kündig, 277-290.

Aguilera y Gamboa, E., Marqués de Cerralbo, 1915, «Torralba. La estación humana más antigua de Europa entre las hoy conocidas", en: IV Congreso de la Asociación Española para el Progreso de las Ciencias (Madrid, 15-20 junio 1913), vol. I, Madrid: Imprenta de Fortanet, 197-210.

Ayarzagüena Sanz, M., 2006, «Altamira en el Congreso Internacional de Antropología y Arqueología Prehistóricas de Lisboa de 1880», Zona Arqueológica 7 (1), Miscelánea en homenaje a Victoria Cabrera, 41-46.

Blanckaert, C., 1993, "Les bases de la civilisation. Lectures de L'homme primitif de Louis Figuier (1870)», Bulletin de la Société préhistorique française 90 , n. ${ }^{\circ} 1,31-49$.

Barreiro Fernández, X. R., 2003, «O Estudio crítico das obras do P. Feijóo de Pardo Bazán, Concepción Arenal e Miguel Morayta. O certame de Ourense de 1878», La Tribuna. Cadernos de Estudos da Casa Museo Emilia Pardo Bazán 1, 47-95.

Barril Vicente, M., 2016, «El marqués de Cerralbo y la arqueología soriana», BolMAN 34, 121-138.

Bravo-Villasante, C., 1962, Vida y obra de Emilia Pardo Bazán, Madrid: Revista de Occidente.

Burdiel, I., 2019, Emilia Pardo Bazán, Madrid: Taurus.

Caballé, A., 2018, Concepción Arenal. La caminante y su sombra, Barcelona: Penguin Random House Grupo Editorial.

Cabré Aguiló, J., 1915, El Arte Rupestre en España (regiones septentrionales y orientales) [Memorias de la Comisión de Investigaciones Paleontológicas y Prehistóricas, 1], Madrid: Junta para Ampliación de Estudios e Investigaciones Científicas.

Cabrera Bosch, M. ${ }^{a}$ I., 2007, «Las mujeres que lucharon solas: Concepción Arenal y Emilia Pardo Bazán», en: P. Folguera (comp.), El feminismo en España: dos siglos de historia, Madrid: Ed. Pablo Iglesias, 45-80.

Capitan, L., 1903, "770e séance.- 16 juillet 1903. Notice sur Paul Jamin», Bulletins et Mémoires de la Société d'anthropologie de Paris Va s., 4, 487-491.

Capitan, L., \& H. Breuil, 1903, «Les figures peintes à l'époque paléolithique sur les parois de la grotte de Font-de-Gaume (Dordogne)», Comptes rendus des séances de l'Académie des Inscriptions et Belles-Lettres 2, 117-129.

Cartailhac, É., 1902, «La grotte d'Altamira, Espagne. Mea culpa d'un scéptique», L'Anthropologie 13, 348-354.

Congrès, 1891, Congrès international d'anthropologie et d'archéologie préhistoriques. Compte rendu de la dixième session à Paris 1889, Paris: Ernest Leroux Éd. 
Cooк, T. A., 1976, El feminismo en la novela de la Condesa de Pardo Bazán, La Coruña: Publicaciones de la Diputación Provincial de La Coruña.

Correa Ramón, A., 2001, El Libro Popular, Madrid: CSIC.

Dagen, P., 1994, «Le 'Premier Artiste'», Romantisme 84, 69-77.

Ducros, A. \& J. Ducros (éds.), 2000, L’homme préhistorique. Images et imaginaire, Paris: L'Harmattan.

Fernández Martínez, V. M., 1991, «La Arqueología de la Imaginación: notas sobre Literatura y Prehistoria», Arqritica 2, 3-6.

Figuier, L., 1870, L'homme primitif. Tableau de la nature. Ouvrage illustré à l'usage de la jeunesse, Paris: Librairie Hachette et $\mathrm{C}^{\mathrm{ie}}$.

Freire López, A. M., 1996, «Feijoo en el siglo xix (Concepción Arenal, Emilia Pardo Bazán y Marcelino Menéndez Pelayo)», en: J. Álvarez Barrientos, J. Checa Beltrán, (eds.), El siglo que llaman ilustrado. Homenaje a Francisco Aguilar Piñal, Madrid: CSIC, 369-374.

Freire López, A. M., 2001, «La primera redacción, autógrafa e inédita, de los 'Apuntes autobiográficos' de Emilia Pardo Bazán», Cuadernos para investigación de la literatura hispánica 26, 305-306.

Glick, T. F., 2010, Darwin en España, València: Publicacions de la Universitat de València.

Guillaumie, M., 2006, Le Roman Préhistorique. Essai de définition d'un genre, essai d'histoire d'un mythe, Limoges: Presses Universitaires de Limoges.

Guillaumie, M., 2013, "Les Nomades de la préhistoire: personnages, récits, images et lecteurs», en: D. Holmes, D. Platten, L. Artiaga, J. Migozzi (eds.), Finding the Plot. Storytelling in Popular Fictions, Newcastle upon Tyne: Cambridge Scholars Publishing, 106-118.

Jiménez Morales, M. a I., 2017, «De la crónica periodística al libro: Cuarenta días en la Exposición (1900), de Emilia Pardo Bazán", La Tribuna. Cadernos de Estudos da Casa Museo Emilia Pardo Bazán 12, 41-62.

Lafont-Couturier, H., P. Dagen, S. Loizeau \& M. P. San Agustín-Filaretos (eds.), 2003, Vénus et Caïn. Figures de la Préhistoire, 1830-1930 [catalogue d'exposition], Paris-Bordeaux: Réunion des Musées Nationaux \& Musée d'Aquitaine.

Lagardère, G. (ed.), 1990, Peintres d'un monde disparu. La préhistoire vue par des artistes de la fin du XIXe siècle à nos jours, Solutré: Musée départemental de préhistoire de Solutré.

Lanzarote Guiral, J. M. a, 2017, "Prehistoria pública: la Exposición de Arte Prehistórico Español de 1921 en la prensa ilustrada española», en: M. Ayarzagüena, G. Mora, J. Salas (eds.), 150 años de Historia de la Arqueología: teoría y método de una disciplina [Memorias de la SEHA III], Madrid: Sociedad Española de Historia de la Arqueología, 789-810.

Martín Rodríguez, M., 2015, «En las cavernas (1912), de Emilia Pardo Bazán, con un breve panorama de la paleoficción literaria española», Dicenda. Cuadernos de Filología Hispánica 33, 163-185.

Moro Abadía, Ó., \& M. R. GonzÁlez Morales, 2004, «1864-1902: el reconocimiento del arte paleolítico", Zephyrus 57, 119-135.

Moser, S., 1998, Ancestral Images. The Iconography of Human Origins, Ithaca, NY: Cornell University Press.

Moser, S. \& C. Gamble, 1997, «Revolutionary Images. The iconic vocabulary for representing human antiquity», en: B. L. Molyneaux (ed.), The Cultural Life of Images. Visual Representation in Archaeology, London \& New York: Routledge, 184-212.

Müller-Schlessel, N., 2001, "Fair Prehistory: archaeological exhibits at French Expositions Universelles», Antiquity 75, 391-401.

Navascués Benlloch, P. de, C. Conde de Beroldingen Geyr \& C. Jiménez Sanz, 1996/2008, El marqués de Cerralbo, Madrid: Ministerio de Cultura.

Pardo BazÁn, E., 1973 (1877), "Reflexiones críticas contra el darwinismo», en: E. Pardo Bazán, Obras Completas, t. III, ed. H. L. Kirby, Jr., Madrid: Aguilar Ed., 537-570.

Pardo Bazán, E., 1886, Apuntes autobiográficos, en: E. Pardo Bazán, Obras Completas, t. III, ed. H. L. Kirby, Jr., Madrid: Aguilar Ed., 1973, 698-732.

Pardo BazÁn, E., 1889, Al pie de la Torre Eiffel. (Crónicas de la Exposición), Madrid: La España Editorial.

Pardo Bazán, E., 1900, Cuarenta días en la Exposición, Madrid: Administración. 
Pardo BazÁN, E., 1903, «Sangre azul», La Ilustración Artística n. ${ }^{\circ}$ 1127, serie «La vida contemporánea», 3 de agosto de 1903, 506.

Pardo BazÁn, E., 1907, «Progreso», Los Lunes de El Imparcial, El Imparcial n. ${ }^{\circ}$ 14.511, 12 de agosto, 3, en: E. Pardo Bazán, Obras Completas, t. III, ed. H. L. Kirby, Jr., Madrid: Aguilar Ed., 1973, 196-198.

Pardo BazÁn, E., 1912, En las cavernas [El Libro Popular. Revista literaria 2], ilustraciones de Luis Checa, Madrid: Impr. De Gabriel López del Horno, en: E. Pardo Bazán, Obras Completas, t. II, ed. F. C. Sainz de Robles, Madrid: Aguilar Ed., 1964, 1031-1051.

Pardo BazÁn, E., 1914, «La vida contemporánea», La Ilustración Artística n. ${ }^{\circ}$ 1.711, 12 de octubre de $1914,670$.

Pardo Bazán, E., 2019, El encaje roto. Antología de cuentos de violencia contra las mujeres (ed. de C. Patińo Eirín), Zaragoza: Ed. Contraseña.

Paredes Núñez, J., 1979, Los cuentos de Emilia Pardo Bazán, Granada: Universidad de Granada.

Paredes Núñez, J., 1992, «El feminismo de Emilia Pardo Bazán», Cuadernos de Estudios Gallegos XL, 105, 303-313.

Pelayo, F., 2015, «El impacto del darwinismo en la sociedad española del siglo XIX», Hispania Nova 13, 309-329, en http://www.uc3m.es/hispanianova.

Quesada Novás, Á., 2006, «Una meta alcanzada: la cátedra universitaria de Emilia Pardo Bazán», La Tribuna. Cadernos de Estudos da Casa Museo Emilia Pardo Bazán 4, 43-80.

ReINaCH, S., 1903, «L'Art et la magie», L'Anthropologie 14, 257-266.

ReInACH, S., 1913, Répertoire de l'art quaternaire, Paris: Ernest Leroux Éditeur.

Richard, N., 1993, "De l'art ludique à l'art magique. Interprétations de l'art parietal au xixe siècle», Bulletin de la Société préhistorique française 90 , n. ${ }^{\circ}$ 1, 60-68.

Richard, N., 2012, «Archaeology, Biology, Anthropology: Human Evolution According to Gabriel de Mortillet and John Lubbock (France, England c. 1860-1870)», History and Philosophy of the Life Sciences 34, 9-32.

Ruddick, N., 2009, The Fire in the Stone. Prehistoric Fiction from Charles Darwin to Jean M. Auel, Middletown, CT: Wesleyan University Press.

Santonja, M., A. Pérez González \& R. Flores, 2005, «Torralba, Ambrona y el Marqués de Cerralbo. Las dos primeras excavaciones del Paleolítico Inferior en España», Zona Arqueológica 5, 19-38.

Stoczkowski, V., 1997, «The Painter and Prehistoric People. A 'hypothesis on canvas'», en: B. L. Molyneaux (ed.), The Cultural Life of Images. Visual Representation in Archaeology, London \& New York: Routledge, 249-262.

Trinidad, F., 2009, «Una semblanza olvidada de Emilia Pardo Bazán», La Tribuna. Cadernos de Estudos da Casa Museo Emilia Pardo Bazán 7, 433-447.

VÁzQuez de Parga, S., 1993, «La novela de ambiente prehistórico», Cuadernos de Literatura Infantil y Juvenil 56, 17-21.

Vilanova y Piera, J., 1890, "Congreso de antropología y de arqueología prehistóricas», celebrado en París en agosto de 1889", BRAH XVII, 108-113.

Villacorta Baños, F., 1979, «El Ateneo de Madrid (1896-1907): la Escuela de Estudios Superiores y la extensión universitaria», Hispania 39 n. ${ }^{\circ} 41,101-158$. 